\title{
Assessing Visualization Abilities in Minority Engineering Students
}

\author{
N. E. Study \\ Department of Engineering, ENTC, INTC \\ Virginia State University, Petersburg, VA 23806
}

\begin{abstract}
The numbers of minority students in the academic areas of science and engineering (S\&E) have increased significantly in recent years. Despite initial success in recruitment efforts, the numbers of these minority students not completing their studies still remain higher than that of their non-minority peers. Visualization is a significant factor in the creation of mental models and in interacting with the often abstract concepts that are important for success in S\&E fields. An ongoing study recently found that a particular sample of minority engineering and technology students at a historically black university scored statistically significantly lower on the Purdue Spatial Visualization Test: Visualization of Rotations (PSVT) than did a sample of non-minority engineering students at a primarily majority serving institution. This paper discusses those PSVT pretest results and the results of the same test given as a posttest following a semester of instruction. The pretest scores of the initial sample of minority subjects are also compared to another group of minority subjects who took the same course in a following semester. Factors potentially affecting the success and preparation level of the subjects are also addressed including previous academic achievement, scores on standardized tests, and entry requirements of the different institutions the subjects attend.
\end{abstract}

Introduction

In recent years, there has been considerable effort put into increasing the numbers of minorities in the academic fields of engineering, science, and technology. Despite the increased recruitment efforts, and the larger numbers of minorities actually beginning studies in the fields of engineering, science, and technology, the numbers of minorities in these fields not completing their studies remains at a higher rate than those of the non-minority population. The overall national average college graduation rate for black students is 38 percent, compared to 60 percent for white students and the graduation rate at historically black colleges and universities (HBCUs) is even lower than that with more than two thirds of entering freshman not going on to earn degrees ${ }^{[1]}$.

Spatial visualization ability has been linked with academic success in the S\&E fields and can be an important factor for success in the creation of mental models and in interacting with abstract concepts. The minority subjects in this study had significantly lower visualization abilities than did their non-minority counterparts. Although some research has shown declines in 
gender differences in spatial visualization ability due to a variety of factors in recent years, little research has been done specifically with minority populations other than women. With minorities leaving their engineering, science, and technology studies at a higher rate than nonminorities, it is important to address factors that may inhibit their continuation with their studies. Therefore, the focus of this paper is to compare the pre and posttest scores of minority engineering students in a beginning engineering drawing course at a historically black university to those of students in a primarily non-minority population at a majority serving institution.

\section{Minorities in Science and Engineering}

The numbers of women and minorities participating in science and engineering (S\&E) higher education in the United States continues to rise but the percentages are still not equal to their representation in the population ${ }^{[2]}$. In 2001-2, blacks were 14 percent of the U.S. population, yet in the same year, the percentage of engineering bachelor's degrees earned by blacks was only 5.4 percent $^{[3]}$. The number of minorities who are prospective majors in S\&E drops sharply between the senior year of high school and the junior year at university, therefore the first years at university provide a critical opportunity to retain minorities in the S\&E fields.

Precollege preparation in mathematics and science is an important indicator of success for undergraduate majors in science and engineering. Although the percentages of minority students taking higher level mathematics and science courses in high school have increased in recent years, the numbers are still well below those of non-minority students. Differences in race/ethnicity also exist in the proficiency levels in mathematics and science scores at the $4^{\text {th }}, 8^{\text {th }}$, and $12^{\text {th }}$ grade levels with white students having significantly higher scores at all levels ${ }^{[4]}$.

According to Impelluso ${ }^{[5]}$, students who begin studies in engineering "with less real world experience with mechanical objects are at a considerable disadvantage when they enter the lab and try to construct objects alongside more experienced classmates who have had time to develop their own visualizations or 'mental models' about how things work." Overall, minorities and women entering S\&E fields tend to have less previous experience with technology and computing and report greater lack of confidence and more negative encounters with technology than non-minorities ${ }^{[6]}$. The reasons minorities often gave for their leaving studies in S\&E were a lack of confidence combined with courses often being taught in a decontextualized, abstract and non-interactive manner ${ }^{[7]}$. If students can learn to visualize and create mental models, this can lead to the development of deeper, higher-order understandings of the particular concept being taught which can then increase student confidence and potentially lead to higher levels of retention of minority S\&E students.

\section{Purdue Spatial Visualization Test: Visualization of Rotations}

The Purdue Spatial Visualization Test: Visualization of Rotations (PSVT) tends to have high construct validity in the area of spatial visualization ability and appears to measure spatial orientation $^{[8]}$. The PSVT consists of 30 items of varying difficulty and is a 20 minute timed test appropriate for individuals age 13 and older. The test consists of items of four types, one type requiring rotation of $90^{\circ}$ about one axis, another requiring rotation of $180^{\circ}$ about one axis, one 
requiring rotation of $90^{\circ}$ about two axes, and the fourth requiring rotation of $90^{\circ}$ about one axis and $180^{\circ}$ about another axis ${ }^{[9]}$. An example is shown in Figure 1.

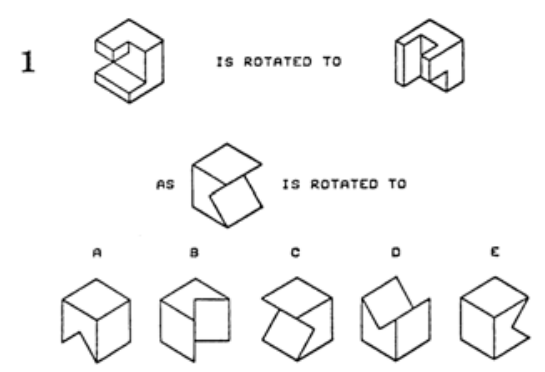

Figure 1. PSVT

Test Results

The PSVT was administered during week one of the semester to engineering and technology students enrolled in introductory engineering drawing courses, in the Fall semester 2003, at Virginia State University, a historically black university. Subjects included 27 males and one female. The mean age was 19.5 years with a range from 17 to 26 . Semester classifications were 28.6 percent semester $1,28.6$ percent semester $3,17.9$ percent semester 5, 14.3 percent semester $2,7.1$ percent semester 4 , and 3.6 percent semester 7 .

The pretest scores of these minority students were compared to a set of data obtained from 421 predominantly non-minority students enrolled in an introduction to graphics for manufacturing course, in the Fall semester 2001 on the West Lafayette campus of Purdue University. This test was administered during week one of the semester. Subjects were 81 percent male and 19 percent female and ranged in age from 17 to 27 with a mean age of 18.6. Eighty-nine percent were Freshman Engineering majors in the Schools of Engineering; the remaining 11 percent were non-engineering majors. Semester classifications were 61 percent semester $1,37.2$ percent semester $3,1.4$ percent semester 3 and 0.5 percent semester $8^{[10]}$.

The minority population's pretest PSVT score distribution is shown in the histogram in Figure 2. The mean score was 13.6 with a range from 5 to 23 . Scores were slightly positively skewed with a value of .363 , which is not out of the range of normality.

The non-minority population's PSVT score distribution is shown in the histogram in Figure 3. The mean score was 24.2 with a range from 10 to 30 . The scores were skewed negatively at -.918 , but were not out of range of normality ${ }^{[10]}$. 


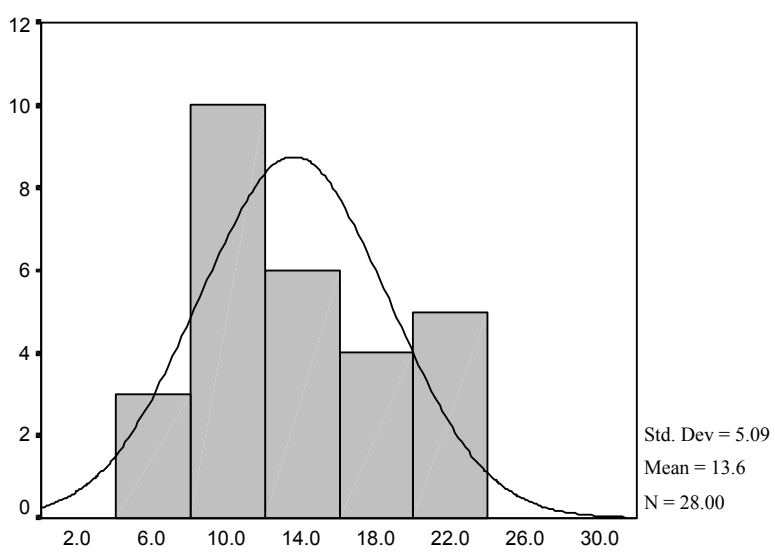

Figure 2. Minority PSVT Pretest Scores

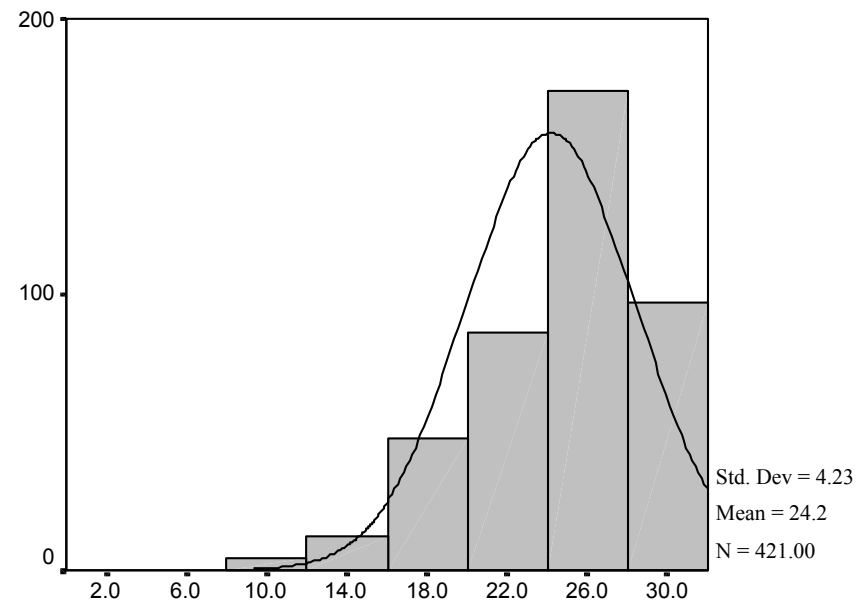

Figure 3. Non-minority PSVT Pretest Scores

An analysis of variance (ANOVA) was run to compare the minority pretest scores to the non-minority scores and the results were significant at the $\alpha=.01$ level, as shown in Figure 4 .

ANOVA

SCORES
\begin{tabular}{|l|c|c|c|c|c|}
\hline & $\begin{array}{c}\text { Sum of } \\
\text { Squares }\end{array}$ & df & Mean Square & F & Sig. \\
\hline $\begin{array}{l}\text { Between } \\
\text { Groups } \\
\text { Within } \\
\text { Groups }\end{array}$ & 2950.98 & 1 & 2950.98 & 160.61 & 0.00 \\
Total & 8213.20 & 447 & 18.37 & & \\
\hline
\end{tabular}

Figure 4. ANOVA of Minority and Non-minority Pretest PSVT Scores 
The minority population was administered the PSVT as a posttest at the end of the semester. The score distribution is shown in the histogram in Figure 5. The mean score was 17.7 with a range from 6 to 30 . The posttest had 23 subjects, 22 males and 1 female, 5 subjects had dropped the class during the semester.

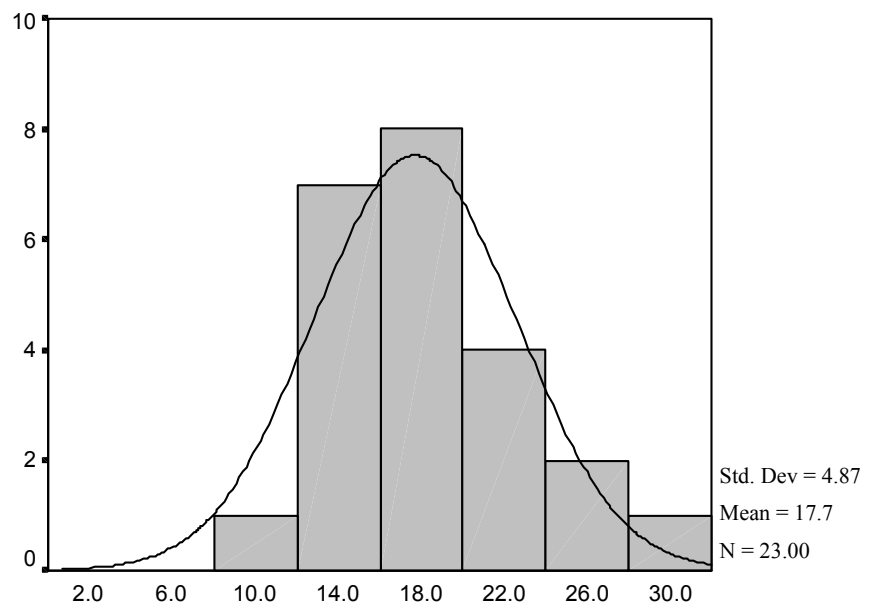

Figure 5. Minority PSVT Posttest Scores

ANOVA
\begin{tabular}{|l|c|c|c|c|c|}
\hline \multicolumn{1}{|c|}{ SCORES } & Sum of Squares & df & Mean Square & F & Sig. \\
\hline Between Groups & 214.783 & 1 & 214.783 & 8.614 & 0.005 \\
Within Groups & 1221.727 & 49 & 24.933 & & \\
Total & 1436.510 & 50 & & & \\
\hline
\end{tabular}

Figure 6. ANOVA for Minority Pretest and Posttest Scores

An analysis of variance (ANOVA) was run to compare the minority pretest scores to their posttest scores and the results were significant at the $\alpha=.01$ level, as shown in Figure 6 .

In the Spring 2004 semester, a group of predominantly minority subjects in another introductory engineering graphics course at Virginia State University were administered the PSVT as a pretest to be used as a comparison to the Fall 2003 group. The scores of these subjects are show in Figure 7. There were 8 male and 3 female subjects in this group. The mean score was 14.6 with a standard deviation 4.78. An ANOVA was run to compare the pretest scores of the Fall 2003 and Spring 2004 subjects and there was no statistically significant difference between the two as shown in Figure 8. 


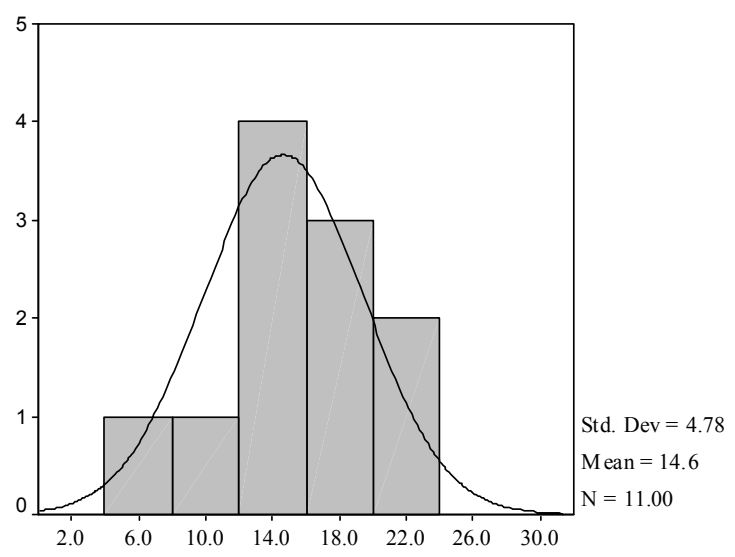

Figure 7. Minority PSVT Pretest Scores for Comparison

ANOVA
Pretest Scores
\begin{tabular}{|l|r|r|r|r|r|}
\hline & Sum of Squares & df & Mean Square & F & \multicolumn{1}{c|}{ Sig. } \\
\hline Between Groups & 8.956 & 1 & 8.956 & 0.357 & 0.554 \\
Within Groups & 929.403 & 37 & 25.119 & & \\
Total & 938.359 & 38 & & & \\
\hline
\end{tabular}

Figure 8. ANOVA of Fall 03 and Spring 04 Pretest Scores

Discussion

The mean pretest score of 13.6 on the PSVT for the minority subjects in the Fall 2003 group was significantly lower at the $\alpha=.01$ level than the mean score for the non-minority subjects of 24.2. Furthermore, the highest score achieved in the minority population, 23, was lower than the mean score for the non-minority population. This group of minority subjects did not appear to be an anomaly as their scores were not statistically significantly different than a comparison group of predominantly minority subjects from the Spring 2004 semester who had a mean score of 14.6

At the end of a semester of instruction which covered topics such as orthographic projection, section and auxiliary views, sketching and CAD work, the minority students were given the PSVT as a posttest in the Fall of 2003. Although the scores did show a statistically significant improvement from a pretest mean of 13.6 to a posttest mean of 17.7 , with a range of 9 to 28 , the posttest mean was still below the mean of the pretest for non-minorities of 24.2.

In some aspects, the differences in these scores could be attributed to the variation in requirements for entry into the academic programs, resulting in populations with dissimilar academic backgrounds and qualifications.

The basic requirements for entry into the freshman engineering program at Purdue University are: 
1. High school diploma or GED - All applicants must either graduate from high school or have a GED.

2. Subject-matter Requirements - Purdue has established subject-matter requirements in English, math, and laboratory science; students who graduate from high school starting in 2004 will have foreign language requirements as well.

Minimum requirements for engineering are:

- 6 semesters Academic Math (algebra, geometry \& trig)

- 4 semesters Lab Science (including 2 chemistry)

- 8 semesters English

Note: Most students who are admitted to Purdue take more than the minimum number of semesters required in math and lab science. In Fall 1999, 97\% of first-year engineering students, excluding international students, exceeded their subject-matter requirements.

3. Quality Requirements - Applicants who meet the minimum subject-matter requirements are evaluated on the basis of quality. Quality includes much more than just high school class rank; it also encompasses your probability of success, overall grade average, grade average in degree-related subjects, trends in achievement, SAT and/or ACT scores, and the strength of your college prep program. Students who attend a non-accredited high school or who are home schooled are strongly encouraged to take SAT II tests in English, math, and a lab science $^{[11]}$.

The entry requirements for Virginia State University are:

1. Official high school transcript or official GED scores

2. SAT or ACT scores

3. Two letters of recommendation

4. Personal Statement

5. A cumulative 2.0 GPA ("C" "average or higher) on a 4.0 scale

- 4 Units of English

- 3 Units of Mathematics (must include Algebra I, and either Geometry or Algebra II)

- $2 / 3$ Units of Science (one of which must be a laboratory science)

- 2 Units of Social Studies (History, Government, Civics, Geography)

- 2 Units of Foreign Language are recommended but not required

All students anticipating enrollment as majors in the Engineering/Technology Programs should have an SAT Math score of at least 400 or three years of high school mathematics with GPA of 2.0, and at least two years of physical science, preferably physics and chemistry ${ }^{[12]}$.

The differences in academic requirements for acceptance into the university may account in part for the differences in the test scores. This is not to say that there is a difference in overall intellectual capacity because spatial visualization abilities are not always associated with traditional concepts of intellectual achievement. 
One major view concerning the construct of intelligence is that there is a general intelligence or general cognitive ability, often referred to as "g" by scholars such as Spearman and Jensen. Modern education is often based on linguistic and logical-mathematical abilities, which is why "g" has been shown to predict success in school with some degree of accuracy ${ }^{[13]}$. Most aptitude tests measure a common core of elements in "g" along with some specific elements ${ }^{[14]}$. But fundamental to spatial intelligence are the abilities to accurately perceive the visual world, to perform transformations and modifications upon initial visual perceptions, and to recreate aspects of a visual experience in the absence of relevant physical stimuli ${ }^{[13]}$. These abilities are not typically measured in traditional tests of achievement yet visualization ability is necessary for success in engineering and engineering graphics related courses.

Tests that measure visualization ability may require a subject to produce forms or manipulate ones that have been provided for them. The ability to produce forms should not be considered identical to the ability to manipulate them in that a subject may have acute abilities in visual perception but little ability to draw, imagine, or transform an absent world. Yet, a subject with skills in several of these areas is most likely to achieve success in the spatial domain and practice in one of these areas stimulates development of skills in related areas ${ }^{[13]}$.

Traditional methods of testing, including those tests which measure " $\mathrm{g}$ " type intelligence have often been found to be biased against minority populations. Tests measuring visualperceptual processing, which do not focus on linguistic or logical-mathematical abilities, have been deemed as more culturally fair measures of aptitude than other measures of intellectual abilities that tend to focus on "g" type intelligence. But used alone, there is little evidence that relying on the results of these visual-perceptual processing tests would result in a more equitable identification of scholastic abilities in minority students ${ }^{[15]}$.

Since spatial visualization skills can be developed through instruction, it should also be considered that the low spatial visualization abilities of the minority students, as shown by the significant difference in PSVT scores, might be due to a lack of previous exposure to the type of educational activities that lead to the development of visualization skills. Therefore, it is not a lack of "g" type intelligence that accounts for the differences in the test scores, but disparity in educational background. It is possible the minority subjects in this study are inadequately prepared for activities at the university level that require spatial visualization skills.

Typically, students admitted to the Freshman Engineering Program at Purdue University are A and B students in high school and in 2002, the Freshman Engineering class members had an average standardized test score of 1269 on the SAT or 29 on the ACT. They had also met the minimum admission requirements of 6 semesters of academic math and 4 semesters of lab science including 2 chemistry courses ${ }^{[11]}$. This is a higher level of academic preparation than is required at Virginia State University where a 2.0 GPA, a score of 400 in the math portion of the SAT, and at least two years of physical science, preferably physics and chemistry are the suggested requirements for entry into the program. The average combined SAT score at VSU is less than 800 .

Studies have shown that the use of visualization in math and science related courses enhances both the visualization skills of students and the learning outcomes of the math and 
science related courses. Hands on experiences, field observations, use of graphing calculators, and science laboratory equipment increased opportunities for the students to create mental models which they could then relate to different academic areas and to daily life ${ }^{[16]}$.

Nevertheless, many high school students in the U.S. receive only superficial preparation in math and science courses and the National Commission on Mathematics and Science Teaching for the 21 st Century deems this unacceptable. Additionally, in schools with the highest minority enrollments, students have less than a 50\% chance of having science or mathematics teachers who hold a license or degree in the subject being taught. Disparities between minority and nonminority success in math and science were accounted for almost entirely by differences in the qualifications of their teachers ${ }^{[17]}$.

Currently at Virginia State University, data collected between the Fall of 1997 and Spring of 2002 showed that 72 percent of freshmen were retained in engineering and technology majors between the first and second semesters of their freshman year. However, the headcount of students who gained sophomore status within one academic year of entering as a freshman was only 37 percent $^{[18]}$. The courses in engineering graphics for the students are typically taken either during the freshman year or the first semester of the sophomore year. If effective remediation were to take place during this first year, there is the potential that it could positively affect the retention rate of these students.

Although one course in engineering graphics can not make up for overall inadequate precollege preparation, studies such as those conducted by Sorby at Michigan Technological University ${ }^{[19]}$ showed that women, who had similarly low pretest scores as did the minority population in this study, with adequate remediation in a spatial skills course, could improve their test scores to the level of non-minority males. In Sorby's study, over the long term, subjects who initially scored low on the PSVT and then enrolled a spatial skills course had significantly higher GPAs in subsequent engineering graphics courses than did a comparison group. The rate of retention in engineering was also significantly higher for those subjects who took a spatial skills course for remediation than for those who did not.

\section{Conclusions}

Visualization is an important aspect of success in the fields of science and engineering. Even though larger numbers of minorities are being recruited into these fields of study, minority students leave science and engineering majors at a rate higher than non-minorities, particularly at HBCUs. To fully reap the benefits of minority recruitment efforts, it is essential to assist these students in overcoming barriers that may discourage their continued education. One of the barriers is the disparity in visualization abilities indicated by the low scores of minority subjects taking the PSVT.

When compared to a sample of non-minority subjects, the PSVT scores of minority subjects in this study were statistically significantly lower. The nonverbal nature of the PSVT should remove potential cultural and language bias that is often noted as a cause for disparity in test scores when comparing minority to non-minority populations and the differences in the test scores can then be attributed to other factors. 
There are many factors that could contribute to the low visualization scores of the minority subjects including inequality in educational background of the incoming students related to lower acceptance standards at the university level. Students at the non-minority institution were required to have higher levels of math and science in previous academic preparation as well as higher standardized test scores than students at the HBCU. In addition, minority students in general often have a more superficial overall preparation in math and sciences and studies have shown positive correlations between visualization skills and success in math and science. Therefore, the low PSVT scores of minorities may be more a reflection of underdeveloped visualization abilities, rather than a lack of abilities. It is possible that different forms of remediation or alternate methods of instruction will be necessary to further improve test scores and in part attempt to compensate for inadequate precollege preparation.

Even though the minority subjects in this study did show a statistically significant improvement in their visualization scores, their posttest scores were still lower than the mean pretest scores for non-minority subjects. Different methods of supplemental instruction are currently being evaluated for potential implementation into these introductory graphics courses. Pre and posttest data will continue to be collected in future semesters to compare other test scores to the ones in this study in order to more fully assess improvement in visualization abilities of the minority engineering and technology students at this HBCU. The retention rates of students will also be collected and analyzed in reference to student success in introductory graphics courses.

\section{References}

[1] African-American college graduation rates: Intolerably low, and not catching up to whites. (2002, October 31). The Journal of Blacks in Higher Education, 37(89), 89-105.

[2] Olson, K. (1999). Despite increases, women and minorities still underrepresented in undergraduate and graduate S\&E education. National Science Foundation. NSF 99-320, January 15, 1999.

[3] Gibbons, M. (2003). Databytes: Diversity by the numbers. ASEE Prism, 13(4).

[4] National Science Foundation, Division of Science Resources Statistics. (2003). Women, minorities, and persons with disabilities in science and engineering: 2002, NSF 03-312. Arlington, VA.

[5] Impelluso, T. (2001). Physics based virtual machines. Proceedings of the 31 st ASEE/IEEE Frontiers in Education Conference, San Diego, CA, Session F1G.

[6] Tjaden, B.J., \& Tjaden, B.C. (2000). A worldwide, web-based study of the attitudes of college freshmen toward computing. ITiCSE 2000. Helsinki, Finland.

[7] Seymour, E. \& Hewitt, N.M. (1997). Talking about leaving: Why undergraduates leave the sciences. Boulder, CO: Westview Press.

[8] Guay, R.B. (1980). Spatial ability measurement: A critique and an alternative. A paper presented at the 1980 Annual Meeting of the American Educational Research Association, April, Boston, MA. (ERIC Document Reproduction Service No. ED189166).

[9] Guay, R.B. (1976). Purdue Spatial Visualization Test - Visualization of Rotations. West Lafayette, IN. Purdue Research Foundation. 
[10] Study, N.E. (2001). The effectiveness of using the Successive Perception Test I to measure visual-haptic ability in engineering students. Unpublished doctoral dissertation, Purdue University.

[11] Purdue University freshman engineering admission requirements. [on line] Retrieved September 19, 2003, from https://engineering.purdue.edu/FrE/resources_for/prospective/reqs

[12] Virginia State University admissions requirements [on line] Retrieved September 28, 2003, from http://www.vsu.edu/admissions/freshmen.htm

[13] Gardner, H. (1983). Frames of mind: The theory of multiple intelligences. NY: Basic Books.

[14] Ree, M.J., \& Carretta, T.R. (1997). What makes an aptitude test valid? In Dillon, R.F. (Ed.), Handbook on testing (pp. 204-219). Westport, CT: Greenwood Press.

[15] Mills, C.J. \& Ablard, K.E. (1993) The Raven's Progressive Matrices: Its usefulness for identifying gifted/talented students. Roeper Review, Feb/Mar 1993, 15(3) 183-187

[16] Harnisch, D.L., Polzin, J.R., Brunsting, J., Camasta, S., Pfister, H., Mueller, B., Frees, K., Gabric, K., Shope. R.J. (2002). Using visualization to make connections between math and science in high school classrooms. A paper presented at the Society for Information Technology and Teacher Education international conference, Nashville, TN.

[17] National Commission on Mathematics and Science Teaching for the 21st Century (The). (2000). Before it's too late: A report to the nation from The National Commission on Mathematics and Science Teaching for the 21st Century. Retrieved October 4, 2003, from http://www.ed.gov/inits/Math/glenn/index.html

[18] Virginia State University Department of Engineering, Engineering Technology, Industrial Education and Technology headcount by semester data. Obtained January, 2004 from Departmental records.

[19] Sorby, S.A. (2001). A course in spatial visualization and its impact on the retention of women engineering students. Journal of Women and Minorities in Science and Engineering. 7(2) 153-172.

NANCY E. STUDY, Ph.D.

Dr. Study is an Assistant Professor in the Department of Engineering, ENTC, \& INTC at Virginia State University. She formerly was a Visiting Assistant Professor in the Department of Computer Graphics Technology at Purdue University, where she earned her Ph.D., and also taught as an Instructor at Southwest MO State University in the Department of Technology. 